\title{
MOBILIZAÇÃO E PARTICIPACCÃO POLÍTICA NA GESTÃO DOS TERRITÓRIOS RURAIS: EXPERIÊNCIAS SOBRE A GESTÃO SOCIAL NO TERRITÓRIO RURAL DO BAIXO AMAZONAS, AM - BRASIL
}

\author{
Mobilization and political participation on the management of rural territories: \\ experiences about social management in the rural territory at Baixo Amazonas, AM -
} Brazil

Pedro Rapozo
Núcleo de Estudos Socioambientais da Amazônia/NESAM Universidade do Estado do Amazonas-UEA. phrapozo@uea.edu.br

\author{
Juliana Araújo Alves \\ Laboratório de Paisagens, Património e Território/Lab2PT e Centro de Território, Ambiente e \\ Construção/C-TAC. \\ Universidade do Minho, Portugal. \\ jalves.geografia@gmail.com
}

\begin{abstract}
Resumo: Os conceitos de governança e de gestão social no Território Rural do Baixo Amazonas, AM foram monitorados durante 3 anos pela Célula de Acompanhamento e Informação do Baixo Amazonas, AM. A Gestão Social pressupõe a existência de atores sociais e de gestores públicos capazes de levar adiante as estratégias de concentração dos agentes públicos e privados, em torno de um projeto comum de futuro, baseado na promoção dos trunfos de um território e na eliminação das barreiras e constrangimentos a que esse futuro se concretize. A Gestão do CODETER foi pensada a partir dos três eixos que compõem o questionário, a Mobilização e a Participação, o Funcionamento do CODETER como estrutura de governança e, por fim, os Impactos. O primeiro eixo avaliou a organização, a frequência das reuniões e a capacidade de tomada de decisão dos seus membros. O segundo abordou a estrutura, a existência de gaps no seu funcionamento, a natureza da relação entre os atores, bem como o nível de conhecimento destes acerca dos temas que envolvem a política territorial. O terceiro eixo avaliou os efeitos das ações do CODETER na vida dos sujeitos e para o desenvolvimento do território. Do ponto de vista conceitual, os CODETER são compreendidos como espaços de participação e deliberação, i.e., uma instância que congrega os diferentes atores sociais do Território na busca pela convergência e criação de consensos.
\end{abstract}

Palavras-chave: gestão social, governança, CODETER, Territórios Rurais, Baixo Amazonas.

ABSTRACT: The concepts of governance and the social management in the rural territory at Baixo Amazonas, AM were monitorate along 3 years through the 'Célula de Acompanhamento e Informação do Baixo Amazonas, AM'. Social management presupposes the existence of social actors and public managers able to carry out the strategies of concentration of public and private agents, around a common future project, based on the promotion of the assets of a territory and the elimination of barriers and constraints to this future. The Management of the CODETER was thought from the three axes that compose the questionnaire, the Mobilization and the Participation, the Functioning of the CODETER like structure of governance and, finally, the Impacts. The first axis evaluated the organization, the frequency of meetings and the decision-making capacity of its members. The second axis evaluated the structure, the existence of gaps in its functioning, the nature of the relationship between the actors, as well as their level of knowledge about the issues surrounding territorial politics. The third axis evaluated the effects of the actions of the CODETER on the life of the population and 
MOBILIZAÇÃO E PARTICIPAÇÃO POLÍTICA NA GESTÃO DOS TERRITÓRIOS RURAIS: EXPERIÊNCIAS SOBRE A GESTÃO SOCIAL NO TERRITÓRIO RURAL DO BAIXO AMAZONAS, AM - BRASIL

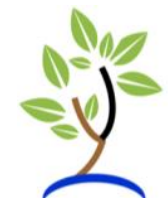

for the development of the territory. From the conceptual point of view, the CODETERs are understood as spaces of participation and deliberation, i.e., an instance that brings together the different social actors of the Territory in the search for convergence and the creation of consensuses.

Key words: social management, governance, CODETER, rural territories, Baixo Amazonas.

\section{INTRODUÇÃO}

No Brasil, a ideia de Gestão Social surge na década de 80 com a redemocratização do Estado, quando se inicia um processo de descentralização política em resposta à crise fiscal nacional visando democratizar as políticas públicas através de uma nova articulação entre a esfera pública e a privada.

Nesse contexto, a Gestão Social configura-se como uma perspectiva inovadora no sentido de se contrapor a modelos de gestão tradicionais fundados na hierarquia, no controle e na racionalização, propondo um novo modelo de interação entre Estado e sociedade, onde o primeiro revê sua suposta primazia na condução dos processos de transformação social e assume a complexidade dos sujeitos e interesses em jogo como essencial para a definição e construção das políticas públicas.

Tal potencial foi então acolhido por grupos estratégicos da sociedade civil organizada que passaram a explorá-lo em sua capacidade de contextualizar experiências criativas de gestão, dando sentido e reconhecimento a iniciativas até então dispersas (BOULLOSA \& SCHOMER, 2008). A partir disso, pela sua própria dinâmica de construção, o termo foi perdendo parte do seu caráter de inovação e, ao invés de se contrapor aos modelos tradicionais de gestão, passa a representar a si mesmo de maneira autônoma.

Pode-se tomar como marco legal desse processo a promulgação da Constituição brasileira de 1988, onde os municípios, enquanto pertencentes a unidade federativa, passariam por uma autonomia no que tange sua concertação com a União e os Estados. Além disso, outros processos sociopolíticos, que investiam em novas matrizes interpretativas, contribuíram para o amadurecimento da noção de gestão social. Dentre eles, podemos citar a difusão de experiências da Agenda 21, a mobilização e articulação de movimentos sociais e organizações da sociedade civil no âmbito mundial, em espaços como o do Fórum Social Mundial, a proclamação do chamado terceiro setor ou do conjunto de organizações da sociedade civil como esfera organizacional distinta do Estado e do mercado, o engajamento de empresas e suas lideranças em movimentos pelo desenvolvimento sustentável e responsabilidade social empresarial (BOULLOSA \& SCHOMMER, 2008).

Embora com quase 30 anos de notoriedade e visibilidade mediática, ainda é muito mais fácil definir o termo gestão social enquanto prática do que propriamente como um conceito. Autores como França Filho (2008) adverte que, a Gestão Social "[...] parece constituir nos últimos anos um daqueles termos que tem conquistado uma visibilidade cada vez maior, tanto do ponto de vista acadêmico, quanto, sobretudo, em termos mediáticos". Esta situação traz alguns problemas segundo o autor, um 
MOBILIZAÇÃO E PARTICIPAÇÃO POLÍTICA NA GESTÃO DOS TERRITỎRIOS RURAIS: EXPERIÊNCIAS SOBRE A GESTÃO SOCIAL NO TERRITÓRIO RURAL DO BAIXO AMAZONAS, AM - BRASIL

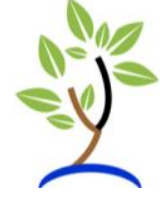

deles seria sua banalização, pois "tudo que não é gestão tradicional passa então a ser visto como gestão social" (FRANÇA FILHO, 2008, p. 26).

Nesta perspectiva, alguns autores, como Tenório (2008) apontam que a gestão social tem sido mais associada à gestão de políticas sociais ou até ambientais, "[...] do que à discussão e possibilidade de uma gestão democrática, participativa, quer na formulação de políticas públicas, quer nas relações de caráter produtivo" (TENÓRIO, 2008, p. 158).

Neste sentido, este artigo analisou a proposta de gestão social bem como a sua aplicabilidade no âmbito do Programa de Desenvolvimento Rural Sustentável Territórios da Cidadania executado pela Secretaria de Desenvolvimento Territorial (SDT) e vinculada ao Ministério do Desenvolvimento Agrário (MDA). O Programa Territórios Rurais da Cidadania configurou-se como uma das iniciativas do Governo Federal à promoção do desenvolvimento em sua perspectiva sustentável e territorial.

As ações do Programa Territórios Rurais da Cidadania, no Estado do Amazonas, foram acompanhadas durante os anos de 2010 a 2013 pela Célula de Acompanhamento e Informação no Território Baixo-Amazonas/AM (Parintins, Barreirinha, Nhamundá, Maués, Boa Vista do Ramos, Urucará e São Sebastião do Uatumã - Figura 1), por meio do Colegiado de Desenvolvimento Territorial (CODETER) do Território do Baixo Amazonas, AM.

De acordo com Marco Referencial para Apoio ao Desenvolvimento de Territórios Rurais, entende-se por Gestão Social:

\footnotetext{
"[...] o processo através do qual o conjunto dos atores sociais de um território se envolve não só nos espaços de deliberação e consulta das políticas para o desenvolvimento, mas sim, e mais amplamente, no conjunto de iniciativas que vão desde a mobilização desses agentes e fatores locais até à implementação e avaliação das ações planejadas, passando pelas etapas de diagnóstico, de elaboração de planos, de negociação de políticas e projetos. Gestão social implica, assim, um constante compartilhamento da responsabilidade pelos destinos do território" (SDT/MDA, 2005, p. 10).
} 


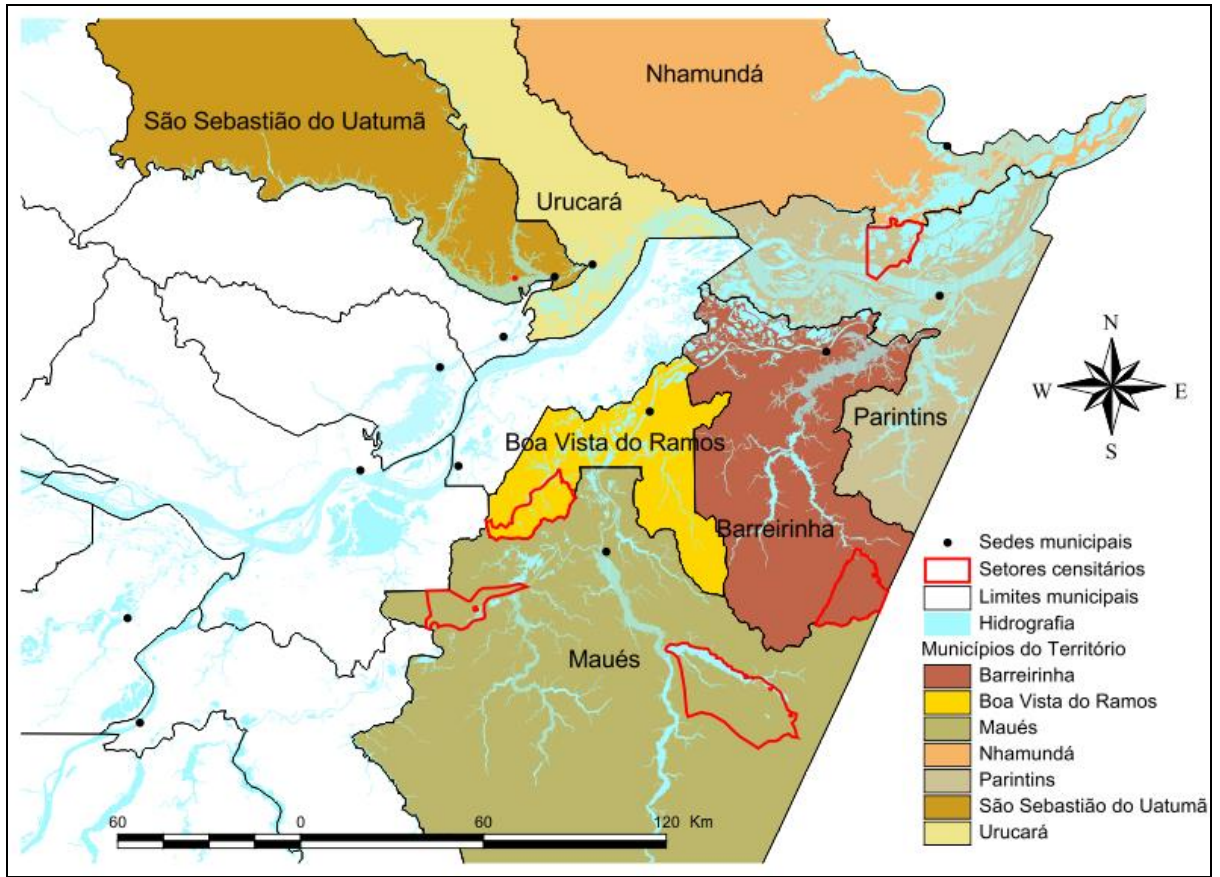

Figura 1: Território do Baixo Amazonas, AM.

Org. Autores, 2019.

Ainda de acordo com o documento supracitado, a noção de Gestão Social pressupõe a existência de atores sociais e de gestores públicos capazes de levar adiante as estratégias de concentração dos agentes públicos e privados, em torno de um projeto comum de futuro, baseado na promoção dos trunfos de um território e na eliminação das barreiras e constrangimentos a que esse futuro se concretize. No entanto, as competências e habilidades demandadas por essa função nem sempre são dadas. Por isso, é preciso que o empoderamento dos atores e instituições seja uma preocupação presente. O empoderamento da sociedade deve contribuir para que as novas institucionalidades sejam capazes de expressar formas mais avançadas e democráticas de governança e de governabilidade democrática, aperfeiçoando as relações vigentes entre o Estado e a sociedade, o que implica uma revisão dos deveres e das obrigações, papéis e atribuições, formalmente instituídas, enfatizando as convergências de interesses que conduzam à articulação de ações (SDT/MDA, 2005).

Nesse sentido, falar de Gestão Social implica necessariamente falarmos de governança territorial, concebida como o exercício do poder e da autoridade por parte dos cidadãos ou grupos devidamente articulados nas suas instituições e organizações, incluindo todos os processos, com o objetivo de diagnosticar a realidade, definir prioridades, planejar a implementação das ações e, assim, determinar como os recursos financeiros, materiais e humanos devam ser alocados, para a dinamização das potencialidades e superação dos desafios, visando o desenvolvimento territorial: 
MOBILIZAÇÃO E PARTICIPAÇÃO POLÍTICA NA GESTÃO DOS TERRITÓRIOS RURAIS: EXPERIÊNCIAS SOBRE A GESTÃO SOCIAL NO TERRITÓRIO RURAL DO BAIXO AMAZONAS, AM - BRASIL

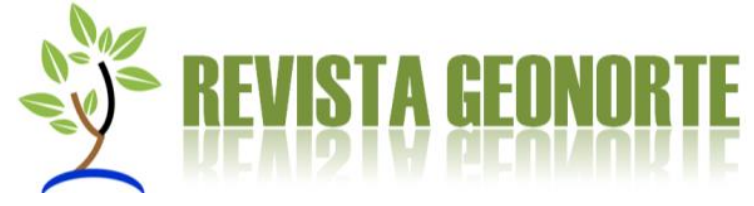

"[...] conjunto de iniciativas ou ações que expressam a capacidade de uma sociedade organizada territorialmente, para gerir os assuntos públicos a partir do envolvimento conjunto e cooperativo dos atores sociais, econômicos e institucionais, como fonte sinergizadora do processo de gestão do desenvolvimento territorial" (DALLABRIDA, 2007, p. 45).

Esse conjunto de iniciativas constitui a dinâmica territorial, que por sua vez está relacionada ao processo de desenvolvimento, empreendida por atores/agentes, organizações/instituições de uma sociedade identificada por aspectos históricos, políticos, econômicos, sociais e culturais que definem o território. Para se efetivar uma proposta dessa natureza, esses atores devem estar organizados em torno de esferas públicas de discussão e deliberação, fóruns que possam abarcar sua multiplicidade e reunir os diferentes contextos políticos e culturais.

Ao procuramos analisar o Colegiado de Desenvolvimento Territorial (CODETER) cerne da gestão social aplicado à política territorial, daremos visibilidade à uma análise sociopolítica de sua funcionalidade e efetividade. Formado dentro do preceito paritário, o CODETER é composto por entidades da sociedade civil e do poder público. Estas entidades são indicadas pelos Conselhos Municipais de Desenvolvimento Rural Sustentável (CMDRS), presentes em cada um dos municípios que compõem o Território. No caso do Território do Baixo Amazonas, o CODETER é formado por cinco representantes de instituições do poder público e cinco representantes da sociedade civil escolhidas em cada um dos sete municípios (Parintins, Barreirinha, Nhamundá, Maués, Boa Vista do Ramos, Urucará e São Sebastião do Uatumã), encerrando a representatividade de setenta instituições. $O$ pleno funcionamento desses espaços é um dos objetivos centrais na estratégia de desenvolvimento territorial, pois embora se torne explícito certas tensões e conflitos de interesses entre os sujeitos, também representa oportunidade para a prática democrática, a busca de convergências e a transparência pública. Este cenário deve refletir a recuperação das noções referentes aos papéis desempenhados pelo Estado e pela Sociedade Civil, repensando-os, sobretudo, sob a ótica da participação cidadã. Nessa conjuntura, o capital social assume grande importância na estruturação dessas instâncias como fator de empoderamento.

Entendido como o conjunto de relações (pessoais, sociais, institucionais) que podem ser mobilizadas pelas pessoas, organizações e movimentos visando a um determinado fim, o capital social tem na sua raiz processos que são ao mesmo tempo baseados e gerados na confiança, reciprocidade e cooperação. Implica a habilidade de pessoas e grupos em estabelecerem relações duradouras, obter recursos financeiros, materiais, cognitivos e empreender ações com a finalidade de reduzir custos das transações por meio da associação, da administração, da compra e da venda conjuntas, do uso compartilhado de bens, da obtenção e difusão de informações (SDT/MDA, 2005).

A articulação entre esses conceitos permeará, e de certa forma direcionará a avaliação a respeito da gestão do colegiado. Uma vez entendido o contexto em que os sujeitos se situam, o objetivo desta investigação foi de perceber o quanto as 
MOBILIZAÇÃO E PARTICIPAÇÃO POLÍTICA NA GESTÃO DOS TERRITÓRIOS RURAIS: EXPERIÊNCIAS SOBRE A GESTÃO SOCIAL NO TERRITÓRIO RURAL DO BAIXO AMAZONAS, AM - BRASIL

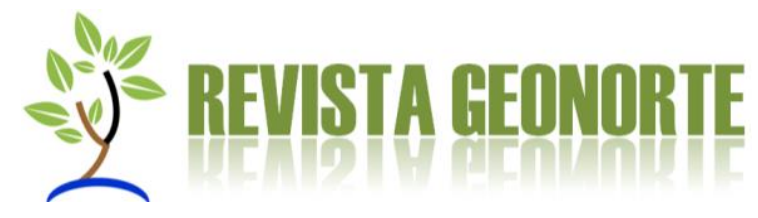

instituições que fazem parte do colegiado evoluiriam em termos de acúmulo de capital social e como isso reflete nos aspectos da gestão.

\section{MATERIAIS E MÉTODOS}

Esta investigação foi realizada com recurso à aplicação de questionários para a avaliação da gestão social dos Territórios Rurais da Cidadania. Foram aplicados 21 questionários com os representantes de instituições elegidas nos municípios e que participavam do CODETER. A pesquisa de campo foi realizada em duas etapas. A primeira etapa foi realizada entre os dias 28 de Novembro e 14 de Dezembro de 2012, nos municípios de Parintins, Nhamundá, Barreirinha, Boa Vista do Ramos e Maués. A segunda etapa foi realizada entre 16 e 22 de Dezembro de 2012, nos municípios de Urucará e São Sebastião do Uatumã.

A gestão do Colegiado de Desenvolvimento Territorial foi pensada a partir dos três eixos que compõem o Questionário: o eixo 1. Mobilização e participação, aborda a organização do Colegiado, a frequência das reuniões e a capacidade de tomada de decisão dos seus membros; $O$ eixo 2. Funcionamento do colegiado como estrutura de governança, trata da estrutura do Colegiado, dos principais problemas que prejudicam o seu funcionamento, da natureza da relação entre os atores e o nível de conhecimento destes acerca dos temas que envolvem a política territorial; Por fim, o eixo 3. Impactos, encerra a avaliação dos efeitos das ações do CODETER na vida dos sujeitos e para o desenvolvimento do Território.

\section{RESULTADOS E DISCUSSÃO}

\section{A MOBILIZAÇÃO E A PARTICIPAÇÃO}

Uma vez que entende-se os Colegiados como espaços de participação e deliberação, i.e., uma instância que congrega os diferentes atores sociais do território na busca pela convergência e criação de consensos, o próprio conceito de participação deve ser explorado. Segundo Tenório \& Rozenberg (1997), a participação integra o cotidiano de todos os indivíduos, uma vez que atuamos sob relações sociais. Por desejo próprio ou não, somos, ao longo da vida, levados a participar de grupos e atividades. Esse ato nos revela a necessidade que temos de nos associar para buscar objetivos, que seriam de difícil consecução ou mesmo inatingíveis se procurássemos alcançá-los individualmente. Assim, a cidadania e a participação referem-se à apropriação pelos indivíduos do direito de construção democrática do seu próprio destino.

Nesta ótica, observou-se os gráficos a seguir, coadunando as análises com as experiências absorvidas durante o trabalho de campo. A Figura 2 diz respeito à avaliação feita pelos membros do CODETER sobre a mobilização dos sujeitos convocados para as reuniões. Para a avaliação foi utilizada uma escala em Likert, variando do nível 1 (Péssimo) até o nível 5 (Ótimo). 


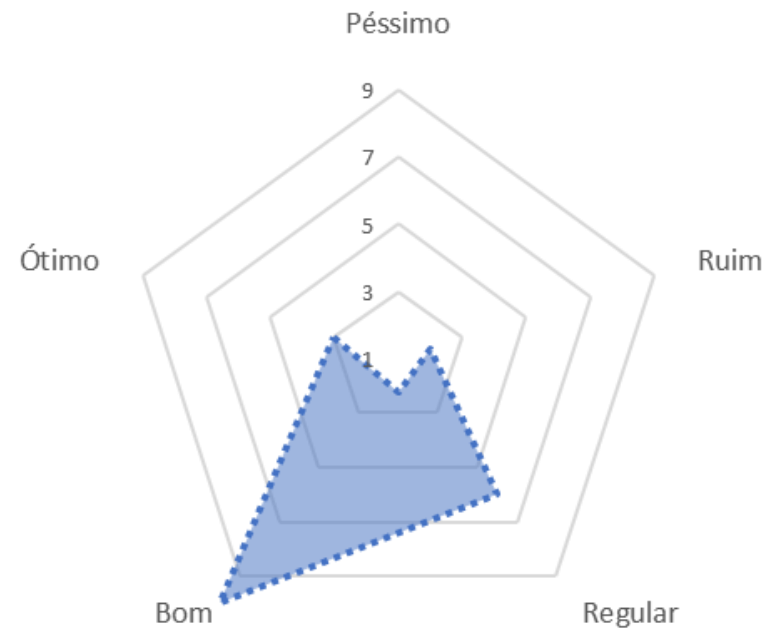

Figura 2: Avaliação da mobilização das pessoas no âmbito do CODETER.

Org. Autores, 2019.

De maneira geral, a mobilização foi avaliada entre o "Regular" e o "Bom". Este resultado pode sugerir que os atores estão engajados na política e participam ativamente das reuniões. No entanto, quando cruzamos esta informação com a frequência dessas reuniões, constatou-se que esta participação 'ativa' não é tão efetiva na prática.

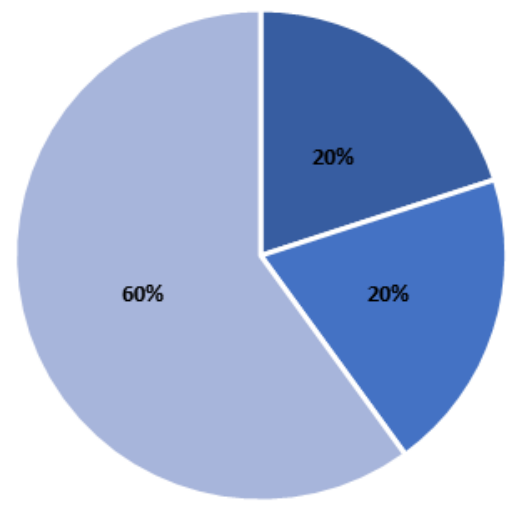

- A cada 3 ou 4 meses - A cada 5 ou 6 meses $=$ Com intervalos superiores a 6 meses

Figura 3: Frequência de reuniões do CODETER.

Org. Autores, 2019.

A realidade é bem mais desalentadora (Figura 3), $60 \%$ dos inquiridos respondeu que os membros se reúnem com intervalos superiores a seis meses. Legalmente, como dita o regimento interno do CODETER, as reuniões deveriam acontecer mensalmente, mas durante a aplicação dos questionários constatou-se que há mais 
MOBILIZAÇÃO E PARTICIPAÇÃO POLÍTICA NA GESTÃO DOS TERRITỎRIOS RURAIS: EXPERIÊNCIAS SOBRE A GESTÃO SOCIAL NO TERRITÓRIO RURAL DO BAIXO AMAZONAS, AM - BRASIL

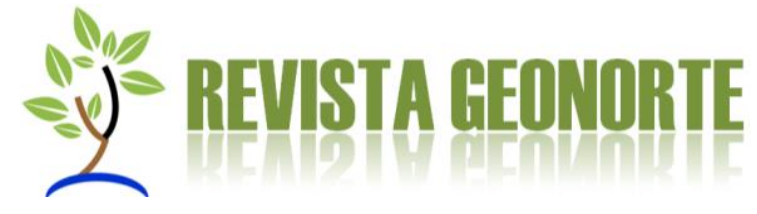

de um ano que não é realizada nenhuma reunião. Observa-se, dessa maneira, um grande contrassenso entre os dados apresentados na Figura 2 e 3 . Inicialmente, os inquiridos percepcionaram positivamente a mobilização do colegiado. No entanto, quando questionados sobre a frequência de reuniões observa-se que a informação não é compatível com a realidade. Estes dados suscitam a seguinte questão: se não há reuniões como é possível que exista efetivamente a participação? Esta disparidade entre as respostas dadas às perguntas e a realidade encontrada transpareceu diversas vezes durante as pesquisas de campo realizadas pela Célula de Acompanhamento e Informação do Território do Baixo Amazonas, AM.

Este cenário pode ser explicado pelo caráter tendencioso do Questionário, que induz os inquiridos a outras respostas pela falta de alternativas adequadas. Algumas questões do Questionário disponibilizado pela SDT não levam em consideração determinadas particularidades que são imprescindíveis para compreender a dinâmica territorial, i.e., pressupõem uma realidade pré-concebida que para os formuladores do instrumento já esta dada a priori. Por outro lado, uma miríade de aspectos culturais ímpares da região Norte do Brasil, muito relacionados com a maneira como os sujeitos se veem e dão sentido às suas experiências, influenciam as respostas. As particularidades do território não são consideradas quando a proposta é formular um instrumento a ser aplicado, indiscriminadamente, em territórios espalhados em regiões muito diversas do Brasil, com características políticas, econômicas e culturais intrinsecamente diferentes.

Os inquiridos justificaram que a falta de orçamento e o mau funcionamento dos CMDRS são as principais causas da baixa frequência de reuniões. Uma reunião exige certos gastos com a hospedagem, o deslocamento e a alimentação para os setenta representantes que compõem o CODETER. O deslocamento na região amazônica é realizado quase que, exclusivamente, por vias fluviais e a despeito do intenso fluxo de embarcações, a disposição geográfica dos municípios faz com que o tempo de viagem seja de até dezoito horas dependendo do ponto de referência. Não se pode olvidar a situação de membros do CODETER que moram em áreas rurais ainda mais distantes. Estes aspectos dificultam a realização de reuniões com a frequência desejada e, mesmo quando conseguem realizar algum evento, raramente contam com a presença de todos.

Segundo Tenório e Rozenberg (1997), a participação ideal deve seguir os seguintes pressupostos:

- Consciência sobre atos: uma participação consciente é aquela em que o envolvido possui compreensão sobre o processo que está vivenciando, do contrário, é restrita;

- Forma de assegurá-la: a participação não pode ser forçada nem aceita como esmola, não podendo ser, assim, uma mera concessão;

- Voluntariedade: o envolvimento deve ocorrer pelo interesse do indivíduo, sem coação ou imposição. 
MOBILIZAÇÃO E PARTICIPAÇÃO POLÍTICA NA GESTÃO DOS TERRITÓRIOS RURAIS: EXPERIÊNCIAS SOBRE A GESTÃO SOCIAL NO TERRITÓRIO RURAL DO BAIXO AMAZONAS, AM - BRASIL

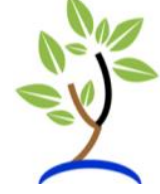

Neste sentido, a participação deve ser construída, não sendo necessária de início uma compreensão totalmente apurada do processo vivenciado, i.e., é somente através desta que se dá o empoderamento dos atores via o acúmulo de capital social. No contexto da política territorial, a geração de capital social se dá desta forma e pela ação do Estado. Peter Evans (1996), destaca a importância da intervenção do Estado na geração de capital social. Para este autor, as características do capital social, como a confiança e o associativismo, podem ser construídas a partir desta intervenção. A falta de engajamento da sociedade civil é decorrente da própria natureza do Estado, uma vez que este tem a capacidade única de mobilização e de organização social.

Ao analisarmos a participação dos segmentos da sociedade civil e do poder público no compartilhamento da gestão, observou-se que são diferenciadas e, mesmo entre os representantes da primeira, existem distinções. A Figura 4 apresenta a capacidade de decisão dos representantes das instituições que fazem parte do colegiado. As respostas utilizam a escala de 1 a 5 , sendo 1 muito baixa e 5 muito alta. Ainda na legenda, NS representa "não sabe" e NA "não se aplica".

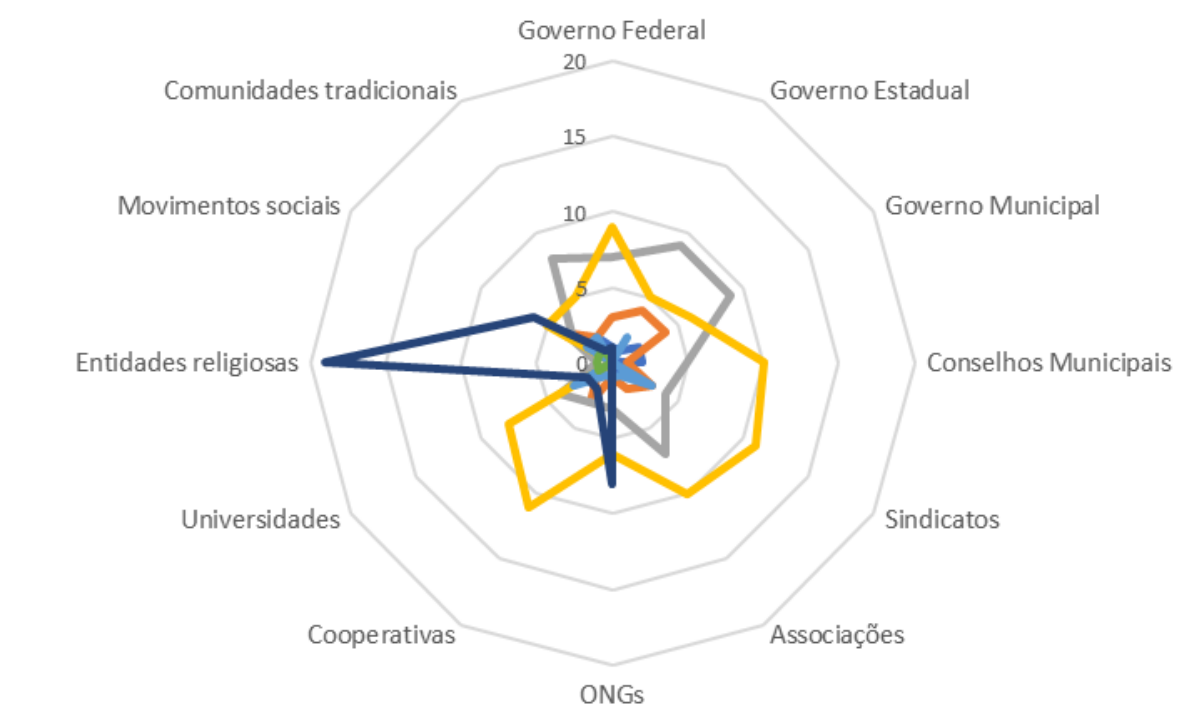

$\longrightarrow$ Muito baixa $\longrightarrow$ Baixa $\longrightarrow$ Moderada $\longrightarrow$ Muito Alta $\longrightarrow$ NS

Figura 4: Capacidade de tomada de decisão dos membros do CODETER.

Org. Autores, 2019.

Neste sentido, a capacidade de decisão do Governo nas escalas Federal, Municipal e Estadual foram avaliados, na sua grande maioria, entre "Moderada" e "Alta". A esfera Federal foi a que apresentou o maior poder de decisão entre as três, sendo a Universidade Federal do Amazonas (UFAM) a única instituição representante. Os Conselhos Municipais, as Associações, os Sindicatos e as Cooperativas 
MOBILIZAÇÃO E PARTICIPAÇÃO POLÍTICA NA GESTÃO DOS TERRITÓRIOS RURAIS: EXPERIÊNCIAS SOBRE A GESTÃO SOCIAL NO TERRITÓRIO RURAL DO BAIXO AMAZONAS, AM - BRASIL

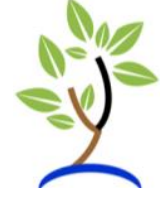

apresentaram um desempenho acima da média. A capacidade de decisão destas entidades foi avaliada, pela maior parte dos inquiridos como "Alta".

Parece-nos existir um comprometimento maior, por parte de alguns segmentos da sociedade civil, em termos de participação e envolvimento com as questões do Território, o que pode ser justificado pelo fato de serem os principais interessados (ou pelo menos se espera que sejam) no desenvolvimento e na melhoria da qualidade de vida da população do Território. Além disso, são estes os elementos que estão mais próximos da realidade e conhecedores das demandas e das necessidades que o dificultoso dia-a-dia do agricultor, do pescador ou do extrativista do Estado do Amazonas suscita.

Porém, infelizmente, a sociedade civil não tem o pleno poder de deliberar e, apesar da capacidade de decisão das instituições representantes deste segmento ter sido avaliada como "Alta", a execução dos encaminhamentos cabe ao poder público. Como levar a cabo as decisões se o poder público muitas vezes não se faz presente, mesmo possuindo, de acordo com os dados, uma grande capacidade para a tomada de decisão? A pouca articulação entre as duas esferas é extremamente prejudicial, entre elas há uma intrínseca relação de dependência, na medida em que uma não existe sem a outra. Quando uma delas não se envolve, vemos o esforço da outra frustrada. A Figura 5 apresenta a evolução da capacidade de decisão do CODETER.

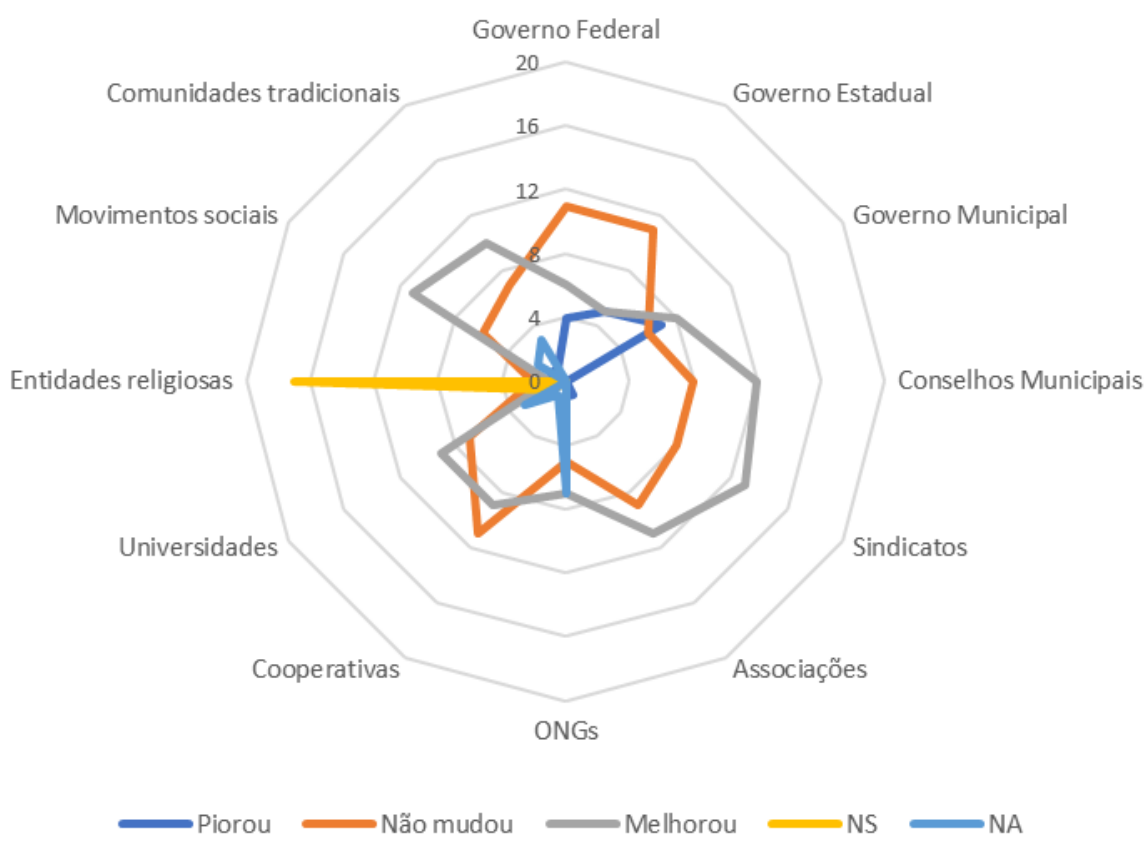

Figura 5: Evolução da capacidade de tomada de decisão dos membros do CODETER. Org. Autores, 2019. 
MOBILIZAÇÃO E PARTICIPAÇÃO POLÍTICA NA GESTÃO DOS TERRITÓRIOS RURAIS: EXPERIÊNCIAS SOBRE A GESTÃO SOCIAL NO TERRITÓRIO RURAL DO BAIXO AMAZONAS, AM - BRASIL

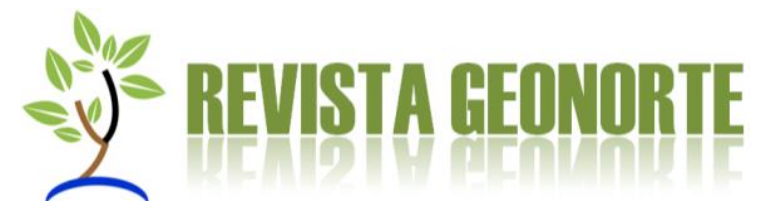

Observou-se que, na medida em que a capacidade de decisão dos membros do poder público "Não Mudou" - com exceção talvez da escala municipal e a respeito da qual é difícil concluir devido à equidade nas respostas - os representantes das entidades da sociedade civil "Melhorou" ou "Não Mudou" na perspectiva dos inquiridos.

Certamente, o envolvimento de determinados segmentos da sociedade civil no CODETER têm sido o maior aprendizado e o maior exercício político que poderiam ter, representa uma oportunidade ímpar para estabelecer trocas e experiências. No entanto, quando se estar a falar de uma importante arena política e esfera pública como esta, é pertinente pensar nas disparidades de aprendizado e vivência política. Obviamente aqueles que possuem maior desenvoltura e prática política poderão levar vantagens nos momentos decisivos e de discussão. Portanto, a institucionalização do espaço do CODETER é um fator que promove a geração de capital social. Os representantes do poder público, apesar da avaliação negativa ("Piorou"), continuam com um alto poder de decisão devido a própria natureza do Estado, que ainda monopoliza, em muitos aspectos, a execução dos encaminhamentos.

Em síntese, os membros do CODETER têm o potencial, ou talvez fosse melhor dizer a vontade para se mobilizar, mas devido a problemas estruturais de orçamento e da dependência do bom funcionamento de outras instâncias, como os CMDRS, vem perdendo o incentivo para isso. Observou-se que, inicialmente, a participação de todas as entidades na gestão social dos projetos e ações do programa era significativa, mas gradualmente, devido a uma série de problemas, os representantes foram perdendo o interesse e deixando de participar ativamente das reuniões e encontros.

\section{O FUNCIONAMENTO DO COLEGIADO COMO ESTRUTURA DE GOVERNANÇA}

Genericamente, o termo governança pode ser definido como um processo complexo de tomada de decisão que antecipa e ultrapassa o governo. Assim, segundo Milani \& Solinís (2002), os aspectos frequentemente evidenciados na literatura sobre governança estão relacionados: à legitimidade do espaço público em constituição, à repartição do poder entre aqueles que governam e aqueles que são governados, aos processos de negociação entre os atores sociais (os procedimentos e as práticas, a gestão das interações e das interdependências que desembocam ou não em sistemas alternativos de regulação, o estabelecimento de redes e mecanismos de coordenação), e por fim, à descentralização da autoridade e das funções ligadas ao ato de governar.

Relativamente à legitimidade do CODETER. As respostas variaram de 1 ("Pouco legítimo") a 5 ("Muito legítimo"). Observa-se que a maior parte dos inquiridos considerou o espaço do CODETER como "Muito legítimo". 
MOBILIZAÇÃO E PARTICIPAÇÃO POLÍTICA NA GESTÃO DOS TERRITỎRIOS RURAIS: EXPERIÊNCIAS SOBRE A GESTÃO SOCIAL NO TERRITÓRIO RURAL DO BAIXO AMAZONAS, AM - BRASIL

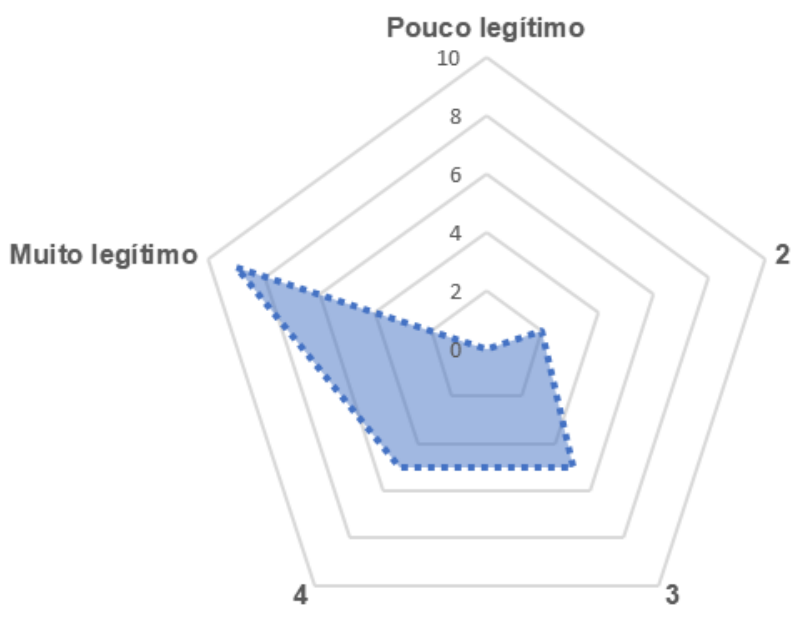

Figura 6: Legitimidade do CODETER.

Org. Autores, 2019.

A definição mais amplamente difundida acerca da legitimidade diz que esta "é a percepção ou pressuposição generalizada de que as ações de uma entidade são desejáveis ou apropriadas dentro de algum sistema socialmente construído de normas, valores, crenças e definições" (SUCHMAN, 1995, p. 574). Como a legitimidade de uma determinada organização, instituição ou entidade não é diretamente acessível, busca-se a sua avaliação pela maneira em que seus atos, práticas, procedimentos e até a própria estrutura tem correspondência e se relacionam com diferentes audiências internas e externas, que são desde os próprios sujeitos envolvidos até o Estado, a sociedade e as outras organizações.

Desta forma, a construção da legitimidade do CODETER se dá primeiro pela ação do Estado, uma vez que é um espaço instituído e formalizado através de uma política pública, refletindo em um modo específico de operacionalizar suas ações, que é visto pelos sujeitos envolvidos como tendo uma origem legítima. Em segundo lugar, estes, a partir de suas percepções, reproduzem esse modus operandi de forma a corroborar com a ideia de legitimidade.

Entretanto, este fato pode suscitar algumas contrariedades. Os sujeitos são incitados a reproduzir práticas com as quais não estão familiarizados e que muitas vezes são conflitantes com os modos de vida e as visões de mundo muito distintas das pensadas pelos formuladores da política pública. Assim, algumas vezes essas práticas são distorcidas em relação àquelas pensadas idealmente. Portanto, 0 espaço ser considerado legítimo ou não, por si só, não garante um bom desempenho, a participação, o envolvimento dos sujeitos e consequentemente nem o funcionamento do CODETER da maneira como foi concebido para funcionar.

O segundo aspecto apontado por Milani \& Solinís (2002) trata da repartição do poder entre governantes e governados. Ao serem questionados se o Colegiado possibilitou uma repartição mais equilibrada do poder no Território, de uma amostra de 21 
MOBILIZAÇÃO E PARTICIPAÇÃO POLÍTICA NA GESTÃO DOS TERRITỎRIOS RURAIS: EXPERIÊNCIAS SOBRE A GESTÃO SOCIAL NO TERRITÓRIO RURAL DO BAIXO AMAZONAS, AM - BRASIL
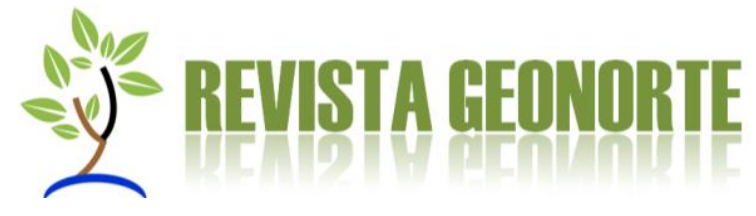

entrevistas, $71,43 \%$ dos entrevistados responderam "Sim" e 28,57\% responderam "Não". Na realidade, os assentos no CODETER estão distribuídos de forma paritária, com metade deles destinados a instituições da sociedade civil e a outra metade destinada aos representantes do poder público. No entanto, observou-se, durante a aplicação dos questionários, uma participação extremamente desigual. Efetivamente no caso do poder público, temos um número muito superior de instituições representantes da esfera municipal, poucas da esfera estadual e apenas uma da esfera federal. Relativamente à sociedade civil, nem todas as instituições são engajadas da mesma forma. Existe uma militância maior por parte das associações, sindicatos e cooperativas, pelo interesse direto que estas têm no estimulo à produção e desenvolvimento do meio rural, potencialidades expressas na gestão do CODETER.

No entanto, de que forma se estabelece esta repartição mais equilibrada do poder? Sobre a existência de grupos hegemônicos no CODETER, 76,19\% dos inquiridos respondeu "Sim". A mesma porcentagem foi registrada para a presença de grupos de interesse. Geralmente esses grupos hegemônicos são formados por aqueles municípios que possuem uma estrutura institucional mais desenvolvida, com os CMDRS mais estruturados. Talvez não seja coincidência que estes municípios também desfrutem de um aparato urbano um pouco mais sofisticado que os outros municípios. Assim, esses grupos se organizam para atrair os projetos de investimentos para as suas sedes, explicitando para além da falácia da repartição equilibrada do poder, a carência de uma visão territorial entre os membros do CODETER.

De acordo com as entrevistas, os principais problemas que prejudicam o funcionamento do colegiado são a "pouca participação dos gestores públicos", "o colegiado não é escutado em outras instâncias" e a "falta de assessor técnico". A pouca participação dos gestores públicos está relacionada com outros fatores como a elevada rotatividade dos membros e a influência política.

A troca constante dos representantes das entidades que compõem o CODETER é um problema sério para o desenvolvimento das atividades. Sempre que há mudança de um representante, formam-se ruídos de comunicação e dispersão de interesses, o que prejudica e compromete, consideravelmente, a participação de cada uma das entidades que formam o CODETER. Quanto à influência política, na Amazônia, como em qualquer outro lugar do Brasil, muitas práticas políticas ainda permanecem submetendo as pessoas aos discursos populistas e enganosos que criam um clima de insatisfação e passividade. Essas práticas têm se caracterizado, em geral, pela apropriação dos recursos públicos para garantir a subordinação política dos grupos sociais mediante o uso de assistencialismo e clientelismo. Essa tendência ao desenvolvimento de práticas tradicionais na política permanece sendo desenvolvida nos diferentes campos de poder, refletindo um cenário de controvérsias e limitações.

O segundo problema apontado como um dos principais entraves diz respeito, diretamente ao terceiro aspecto apresentado no início desta sessão, aos processos de negociação entre os atores sociais. O reconhecimento de que nenhuma organização encerra todos os recursos e competências necessárias para alcançar 
MOBILIZAÇÃO E PARTICIPAÇÃO POLÍTICA NA GESTÃO DOS TERRITỎRIOS RURAIS: EXPERIÊNCIAS SOBRE A GESTÃO SOCIAL NO TERRITÓRIO RURAL DO BAIXO AMAZONAS, AM - BRASIL

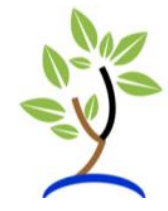

os fins que almeja é o que evidencia a necessidade do estabelecimento de redes de relações, buscando a complementaridade das ações desenvolvidas.

Quando tratamos da relação de pessoas e organizações que mantém contato entre si com um objetivo comum, as estruturas em rede aparecem como chave cognitiva privilegiada na compreensão das mudanças de grande magnitude que ocorrem nas esferas políticas, econômicas e sociais. O problema apontado dificulta imensamente a construção de uma rede confiável que possa prestar apoio ao CODETER, o que gera espaço para o voluntarismo de um ou outro membro na busca por parcerias e patrocínios para apoiar a realização de eventos, oficinas, cursos de capacitação e visitas técnicas. Daí decorre, dentre outras consequências funestas, o grande hiato nas reuniões e a preocupante desmobilização.

Outro problema apontado é a falta de assessor técnico. No geral, os municípios do interior do Amazonas, possuem poucos órgãos de assistência técnica. Alguns destes órgãos contam apenas com a secretaria de produção ou os órgãos de assessoria técnica do governo do Estado do Amazonas. Essas instituições, por sua vez, contam com um número reduzido de técnicos em seus quadros institucionais para atender as diversas áreas rurais, enfrentando problemas que vão desde o deslocamento às comunidades até a própria infraestrutura da organização.

A assistência técnica é um apoio fundamental. Muitas vezes o produtor vê seu cultivo prejudicado por doenças e pragas das quais lhe falta o conhecimento técnico para combater. Da mesma forma, o manuseio inadequado das ferramentas e dos insumos, assim como o desconhecimento de algumas técnicas solapam a produção, refletindo negativamente para o agricultor e para o município, que tem que lidar com déficits no abastecimento.

Neste sentido, este problema pode ser reflexo de uma rede de relações deficiente, mas também não se pode olvidar o quanto é complicado e oneroso para os órgãos de assistência técnica a ampliação do seu contingente de funcionários, devido a uma série de burocracias como a abertura de editais, a realização de concursos públicos e a aquisição de equipamentos, sujeitos via de regra a toda a lentidão inerente ao sistema público.

\section{CONCLUSÃO}

Até aqui discutiu-se a mobilização e a participação dos membros do CODETER e observou-se que há um desequilíbrio tanto no contraponto entre as duas esferas, o poder público e a sociedade civil, como no âmbito de cada uma delas. Apesar dos inquiridos terem avaliado a mobilização como "Boa", há muito tempo não é realizada nenhuma reunião, o que demonstra uma grande incongruência nos dados.

Relativamente ao CODETER, enquanto estrutura de governança, observou-se, com suporte em alguns aspectos evidenciados na literatura, que são muitos os problemas que impedem essa perspectiva de se concretizar. 
MOBILIZAÇÃO E PARTICIPAÇÃO POLÍTICA NA GESTÃO DOS TERRITỎRIOS RURAIS: EXPERIÊNCIAS SOBRE A GESTÃO SOCIAL NO TERRITÓRIO RURAL DO BAIXO AMAZONAS, AM - BRASIL

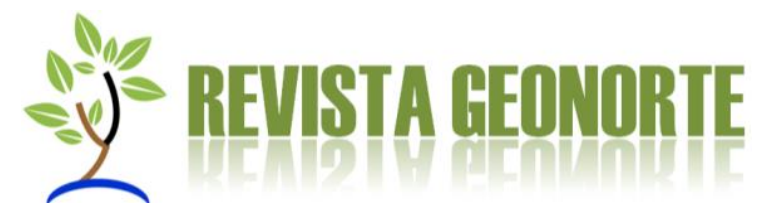

Poder-se-ia apresentar alguns aspectos eleitos para a análise do terceiro eixo, questões abordadas no Questionário como: "O Colegiado possibilitou uma repartição mais equilibrada do poder no território?", "As ações do Colegiado permitiram um equilíbrio entre os grupos de interesse?" ou "A influência do Colegiado na melhoria da relação entre os atores locais?". Para todas estas questões a maior parte dos inquiridos apresentou uma percepção positiva. Ou ainda, poder-se-ia, em um afã otimista, analisar o processo de aprendizagem, e o que ter-se-ia seria nada mais do que o absurdo constatando que os membros do CODETER evoluíram, dentre outras coisas, no sentido de entender as percepções de uma gestão social das políticas públicas. Nesta perspectiva, o cenário seria, portanto, de dados espúrios.

Todavia, durante a realização do trabalho de campo, não só referente à aplicação do instrumento, mas nas diversas oportunidades em que a equipe entrou em contato com o CODETER e seus representantes, foram feitas observações, além de conversas para além do Questionário, e são esses elementos que dão suporte para analisar os verdadeiros impactos. Outros problemas se tornam evidentes quando se considera esta dimensão. O problema da comunicação, que no Questionário só é abordado indiretamente, constitui-se como um dos principais gargalos na consolidação de um processo deliberativo, uma vez que este "[...] baseia-se nas condições de comunicação sob as quais o processo político supõe-se capaz de alcançar resultados racionais, justamente por cumprir-se, em todo seu alcance, de modo deliberativo" (HABERMAS, 2002, p.277).

A deficiência na comunicação não é apenas entre os membros do CODETER, mas principalmente entre os membros do Colegiado e a sociedade civil. A divulgação das (escassas) ações do CODETER não é feita nos municípios que compõem o Território do Baixo Amazonas (AM), tampouco em outros municípios do Estado do Amazonas. A fragilidade no processo de comunicação e informação interfere de modo significativo na construção de uma democracia deliberativa e legítima. Ao contrário do que estava a ser idealizado pelo Programa Territórios Rurais da Cidadania, o processo de empoderamento dos grupos sociais envolvidos no programa se estabeleceu de forma fragmentada, envolvendo no melhor dos casos e mesmo assim de uma maneira muito incipiente apenas os membros do CODETER, um ciclo que se encerrou em si mesmo.

\section{AGRADECIMENTOS}

Esta pesquisa foi financiada com recursos financeiros do CNPq no âmbito do projeto de pesquisa intitulado 'Territórios Rurais do Baixo Amazonas e Entorno de Manaus: Gestão Social para o Desenvolvimento Rural Sustentável' (Processo: 554423/20103). 
MOBILIZAÇÃO E PARTICIPAÇÃO POLÍTICA NA GESTÃO DOS TERRITÓRIOS RURAIS: EXPERIÊNCIAS SOBRE A GESTÃO SOCIAL NO TERRITÓRIO RURAL DO BAIXO AMAZONAS, AM - BRASIL

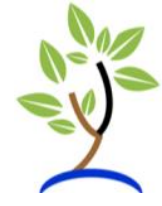

\section{REFERÊNCIAS}

BOULLOSA, R. F.; SCHOMMER, P. C. Gestão Social: caso de inovação em políticas públicas ou mais um caso de Lampedusa? 2008. Disponível em: http://institutofonte.org.br/artigo-gestao-social-inovacao-enigma-de-lampedusa

DALLABRIDA, V. R. A Gestão Social dos Territórios nos Processos de Desenvolvimento Territorial: Uma Aproximação Conceitual. In: Sociedade, Contabilidade e Gestão, Rio de Janeiro, 2007, v. 2, n. 2.

EVANS, P. Government Action, Social Capital and Development: Reviewing the Evidence on Synergy. World Development, 1996, v. 24, N 6, p. 1119-1132.

FRANÇA FILHO, G. C. Gestão Social: um conceito em construção. In: Colóquio Internacional sobre Poder Local, 9, Salvador. Anais do Colóquio Internacional sobre Poder Local, 2008, Salvador: CIAGS/UFBA.

HABERMAS, J. Direito e democracia: entre facticidade e validade. 2003, v. 2. 2 ed.; tradução de Flávio Beno Siebeneichler, Rio de Janeiro: Tempo Brasileiro.

SDT. Secretaria de Desenvolvimento Territorial. Marco Referencial para Apoio ao Desenvolvimento de Territórios Rurais. 2005, Série Documentos Institucionais. Brasília.

MILANI, C.; SOLINÍS, G. Pensar a democracia na governança mundial: algumas pistas para o futuro. In: MILANI, C.; ARTURI, C.; SOLINÍS, G. (Org.), Democracia e governança mundial: que regulações para o século XXI?, 2002, Porto Alegre: Universidade/UFRGS/Unesco, p. 266-291.

SILVA, R. R. Desenvolvimento, capital social e política social, In: Sociedade em Debate, Pelotas, 2007, v. 28 N. 13(1), p. 27-46.

SUCHMAN, M. C. Managing Legitimacy: Strategic and Institutional Approache. Academy of Management Review, 1995, v.20, N. 3, p: 571-610.

TENÓRIO, F. G. A. Tem razão a administração?, 2008, 3 Ed. ljuí: Editora da Unijuí, Ministério do Desenvolvimento Agrário, Secretaria de Desenvolvimento Territorial

TENÓRIO, F. G. \& ROZEMBERG, J. E. Gestão pública e cidadania: metodologias participativas em ação. In: Revista de Administração Pública, Rio de Janeiro: EBAP/ FGV, 1997, v.31, n. 4, p. 101-125.

Recebido em 02/05/2019 Aceito em 01/08/2019 